\title{
Tomada colaborativa de decisão com utilização de teoria dos jogos para o sequenciamento de decolagens em aeroportos
}

\author{
Vitor Filincowsky Ribeiro e Li Weigang²
}

\begin{abstract}
Resumo: Atualmente no Brasil, as decisões no gerenciamento das decolagens de aeronaves dependem exclusivamente da experiência do controlador, que, empiricamente, programa um sequenciamento de partidas. Propõe-se então, através do conceito de Tomada Colaborativa de Decisão (CDM), a elaboração de um sistema computacional para o Gerenciamento Colaborativo de Partidas em aeroportos (CoDMAN) com a utilização da Teoria dos Jogos. Neste modelo, cada agente representa uma aeronave a impactar o cenário aeroportuário e suas decisões são fundamentadas na negociação em cenários dinâmicos multiagentes para a consecução de sequências eficientes de decolagens. Um protótipo foi desenvolvido e foram elaboradas simulações com base em planos de voo válidos para o Aeroporto Internacional de Brasília. A interface com os sistemas radar foi simulada com o tratamento dos voos que impactaram a TMA-Brasília em fevereiro de 2013. Os resultados obtidos foram satisfatórios. As otimizações no sequenciamento das decolagens reduziram o custo associado aos atrasos em até $28 \%$, comprovando a eficácia da modelagem proposta.

Palavras-chave: aeroporto, gerenciamento de tráfego aéreo, teoria dos jogos, tomada colaborativa de decisão.
\end{abstract}

\begin{abstract}
Currently in Brazil the decisions in aircraft departure management depend exclusively on the controller's expertise, which empirically decides the departure sequence scheduling. This work describes the implementation of a Collaborative Departure Management system in airports (CoDMAN) through the concept of Collaborative Decision Making (CDM) with the application of Game Theory. In this model, each agent represents an aircraft that impacts the airport scenario and their decisions are based on the negotiation in dynamic multiagent scenarios in order to yield efficient departure sequences. A prototype was developed with the simulations using flight plans valid to the International Airport of Brasília. The interface with radar systems was also simulated through the evaluation of the impacting flights in TMA-Brasilia during in February 2013 with satisfactory results. The departure sequencing optimization reduced the cost associated to the delays up to $28 \%$, which demonstrates the efficacy of the developed model.
\end{abstract}

Keywords: airport, air traffic management, game theory, collaborative decision making.

\section{INTRODUÇÃO}

Atualmente, nas torres de controle de aeródromos, os controladores contam com sistemas de auxílio ao gerenciamento do fluxo dos pousos e decolagens das aeronaves. No entanto, tais operações nos aeroportos brasileiros são feitas sem auxílio computacional à tomada de decisão quanto à ordenação de partidas e quanto aos tempos de separação entre pousos e decolagens (Weigang et al., 2008). Tal tarefa depende exclusivamente da experiência do controlador (Crespo, 2010). Identifica-se, portanto, a necessidade da utilização de tecnologias de tomada de decisão nos aeroportos brasileiros, pois a atividade de sequenciamento é realizada de forma empírica pelos controladores de voo, os quais devem negociar com as empresas de transporte aéreo o posicionamento das aeronaves sem um critério claro e objetivo.

O Departamento de Controle do Espaço Aéreo do Brasil (DECEA) iniciou a implantação da Navegação Aérea Baseada em Performance (PBN) nos principais aeroportos brasileiros no mês de dezembro de 2013 (DE-

\footnotetext{
1 Vitor Filincowsky Ribeiro, Instituto de Ciências Exatas, Departamento de Ciência da Computação, Laboratório de Pesquisa em Transporte Aéreo (TransLab). Campus Universitário Darcy Ribeiro, Universidade de Brasília UnB - Brasília, DF, Brasil. (filincowsky@gmail.com)

2 Li Weigang, Instituto de Ciências Exatas, Departamento de Ciência da Computação, Laboratório de Pesquisa em Transporte Aéreo (TransLab). Campus Universitário Darcy Ribeiro, Universidade de Brasília - UnB Brasília, DF, Brasil. (weigang@cic.unb.br)

Manuscrito recebido em 30/07/2014 e aprovado para publicação em 10/12/2014.

Este artigo é parte de TRANSPORTES v. 23, n. 1, 2015. ISSN: 2237-1346 (online). DOI:10.14295/transportes.v23i1.828
}

CEA, 2013). Esta atividade faz parte do projeto de implementação do PBN em todo o país e representa um dos vários empreendimentos do programa SIRIUS - Impulsionando o Desenvolvimento do ATM Nacional, da Força Aérea Brasileira (DECEA, 2013), para reestruturação do controle do espaço aéreo no país. Esta implementação é um grande avanço para transporte aéreo nacional. No entanto, ainda não existe um sistema efetivo com a tecnologia CDM no gerenciamento de fluxo aéreo do Brasil.

Observando-se o atual cenário do tráfego aéreo do Brasil e a expectativa de sua demanda de utilização nos próximos anos, propõe-se um mecanismo computacional para gerenciamento de partidas em aeroportos. Para tanto, um embasamento teórico a ser utilizado no desenvolvimento de sistemas de Air Traffic Flow Management (ATFM) é desenvolvido sob os conceitos de Teoria dos Jogos para a negociação entre as aeronaves envolvidas (Ribeiro, 2013). O escopo deste trabalho é especificamente a modelagem Collaborative Departure Management (CoDMAN), que é um mecanismo computacional inteligente para o gerenciamento colaborativo de partidas em aeroportos.

O problema de espera em solo (ground delay problem) pode ser adequadamente modelado segundo estratégias de otimização (Vossen e Ball, 2006). O ambiente aeroportuário é um cenário complexo onde é necessário distribuir recursos entre agentes com objetivos potencialmente conflitantes. A escolha para a Teoria dos Jogos como principal abordagem para a solução deste problema é motivada pelo fato de que os cenários de conflito podem ser considerados jogos onde os agentes assumem determinadas características comportamentais a fim de que seus 
objetivos sejam alcançados (Nash, 1950). Para que a decisão pelas ações dos agentes, ou jogadores, apresente determinado nível de cooperação, é empregado um protocolo de negociação para a obtenção e transferência dos recursos disponíveis.

O objetivo geral da pesquisa é prover um mecanismo computacional para o gerenciamento eficiente de partidas de aeronaves nos aeroportos, ou seja, a proposição de uma modelagem capaz de realizar a alocação e ordenação eficiente das aeronaves na pista de decolagem. Os objetivos específicos são:

- Simulação das situações mais críticas encontradas nos aeroportos, projetando-se cenários sob distintas condições de demanda.

- Desenvolvimento de um algoritmo para o escalonamento de decolagens baseados nos princípios dos algoritmos Ration by Schedule e Compression;

- Elaboração de um algoritmo de Slot Allocation que utilize as técnicas de negociação entre agentes na Teoria dos Jogos para sequenciar a partida de aeronaves;

- A partir de simulações computacionais, identificar vantagens, desvantagens e limitações na implementação e uso do CoDMAN.

$\mathrm{O}$ presente documento é organizado da seguinte forma: a seção 2 introduz os conceitos metodológicos nos quais a pesquisa é embasada. A seção 3 apresenta a modelagem na qual o sistema CoDMAN foi desenvolvido. A seção 4 descreve os casos de simulação e os resultados obtidos. Por fim, a seção 5 encerra o trabalho com as considerações finais da pesquisa.

\section{METODOLOGIA}

Os conceitos teóricos sob os quais o trabalho é desenvolvido consistem em duas principais técnicas: a Teoria dos Jogos e a Tomada Colaborativa de Decisão (CDM), sucintamente descritos na sequência.

\subsection{Teoria dos Jogos}

A Teoria dos Jogos mostra-se uma abordagem adequada para a modelagem do ambiente competitivo no aeroporto, sendo a teoria matemática que estuda o comportamento estratégico de agentes (jogadores) que desejam receber alguma recompensa ao adotarem determinado perfil comportamental em um cenário de atuação específico. Na tentativa de maximizar esta recompensa, o agente decide quais estratégias deve utilizar, e com que probabilidade (Nash, 1950).

\subsubsection{Equilíbrio de Nash}

Em um jogo com $n$ jogadores, o Equilíbrio de Nash é a situação na qual toda escolha individual é a melhor resposta ante o comportamento dos outros $n-1$ jogadores num dado instante (Nash, 1950). Assim, nenhum jogador modificará sua escolha, uma vez que isto não lhe trará melhor resultado (Holt et al., 2004). O Equilíbrio de Nash é uma solução central para um jogo em equilíbrio estratégico.

Em jogos arbitrados, é possível a sugestão estratégica aos jogadores, sendo que alguns deles adotarão outro comportamento se tal sugestão não culminar em um Equi- líbrio de Nash, obtendo assim um melhor resultado (Yildiz, 2010). O Equilíbrio de Nash é, então, um ponto de estabilidade no ajuste dinâmico de comportamentos no qual as escolhas estratégicas são sempre ótimas, de modo que um jogador racional não altera seu comportamento se o jogo já estiver em equilíbrio (Holt et al., 2004).

\subsubsection{Protocolo de Rubinstein}

Agentes podem eventualmente negociar a transferência de recursos entre si. A negociação somente será bem-sucedida se cada agente for racional e tiver completo conhecimento sobre as preferências dos demais jogadores. Logo, este deve ser um jogo de informação perfeita (Manocchio, 2007).

O protocolo de ofertas alternadas de Rubinstein consiste na barganha entre dois indivíduos $p_{1}$ e $p_{2}$ que propõem ofertas um para o outro a fim de que dividam certa quantia monetária $x \in[0,1]$. Em sua vez, cada agente pode aceitar a oferta de seu oponente ou recusá-la, fazendo então uma contraoferta. Para que a negociação não se estenda indefinidamente, a cada rodada é aplicado um fator de desconto à utilidade obtida pelos agentes. Sendo a primeira oferta igual a $(x, 1-x)$, a distribuição de utilidades é igual a $\left(\delta^{i-1} u_{1}(x), \delta^{i-1} u_{2}(x)\right)$, sendo que $\delta \in[0,1]$ é o fator de desconto, atualizado a cada passo iterativo $i$, e os valores $u_{1}(x)$ e $u_{2}(x)$ são, respectivamente, as utilidades obtidas pelos agentes $p_{1}$ e $p_{2}$.

Como este jogo é dinâmico, o processo evolucionário é representado por uma árvore na qual cada nó é um ponto onde um agente decide por aceitar ou rejeitar a oferta (Manocchio, 2007). O jogo termina quando uma oferta é aceita e os resultados são distribuídos. Se a barganha termina sem que haja acordo, um árbitro externo decide pela aplicação de qualquer das ofertas válidas anteriores conforme critério que este achar justo (Yildiz, 2010; Bertsimas et al., 2009).

\subsection{Tomada Colaborativa de Decisão (CDM)}

O processo de alocação eficiente de slots deve contar com a atuação conjunta de todas as entidades impactadas, a fim de que esta operação seja realizada de maneira justa com relação à distribuição dos atrasos (Bertsimas et al., 2009). O compartilhamento de informação entre os agentes para a tomada de decisão é inerente a este cenário colaborativo. Assim sendo, é imprescindível a preocupação com a qualidade da informação, que deve ser completa e atualizada. Este processo colaborativo é chamado de Collaborative Decision Making (CDM), que é um esforço para tornar mais dinâmica e eficiente a atividade de tomada de decisão através do compartilhamento de informações, adequações de procedimentos de gestão, desenvolvimento de ferramentas de suporte e equalização da percepção do cenário entre todas as entidades envolvidas.

A Tomada Colaborativa de Decisão para Aeroportos é utilizada principalmente na Europa e nos EUA, porém surgiu em contextos diferentes (Ball et al., 2000, Eurocontrol, 2010). Nos EUA ela surgiu para tratar o problema da redução das capacidades dos aeroportos, devido às intempéries climáticas. A técnica é chamada de Surface CDM, ou S-CDM (Goldman, 2013). Já na Europa, o CDM é 
direcionado ao aumento da previsibilidade das operações dos aeroportos para evitar que os mesmos se tornassem o gargalo do sistema de gerenciamento de tráfego aéreo. $\mathrm{O}$ CDM aplicado ao contexto aeroportuário recebe o nome de Airport CDM (A-CDM).

A observância dos princípios do CDM permite que decisões sejam feitas de maneira colaborativa, pois os agentes passam a ter completo conhecimento uns sobre os outros, bem como de sua influência no cenário (Groppe $e t$ al., 2010). O sucesso da abordagem depende do compartilhamento de informação completa, precisa e atualizada (Ball et al., 2000). A qualidade da informação é fator determinante para o processo decisório, o que gera responsabilidades para os agentes (Groppe et al., 2010). Como consequência, os atrasos são diminuídos e a capacidade de previsão de eventos é aumentada, otimizando-se desta maneira o gerenciamento dos recursos disponíveis (Eurocontrol, 2010).

\section{MODELAGEM}

O cenário aeroportuário pode ser entendido como um jogo colaborativo onde os agentes divulgam informação pertinente para o processo decisório e recebem o benefício correspondente. O A-CDM pode ser implementado sob os conceitos de Teoria dos Jogos, pois este estudo estratégico é uma abordagem adequada para a modelagem deste tipo de ambiente.

O espaço de atuação das aeronaves sujeitas ao processo de alocação de horários de decolagem é, portanto, um ambiente composto de $n$ jogadores, onde cada um possui uma curva de ganhos com valores definidos por uma função de utilidade. Como não é sempre possível aumentar a utilidade de um agente sem afetar a de outros, busca-se alcançar um estado ótimo, chamado de Ótimo de Pareto (Ribeiro, 2013).

O Equilíbrio de Nash relaciona-se ao quadro competitivo dos agentes, enquanto que o Ótimo de Pareto relaciona-se ao quadro colaborativo. Neste contexto, os voos são os agentes que buscam maximizar a sua eficiência, o que equivale à redução dos custos dos atrasos. Os agentes concorrem pelos recursos de controle de tráfego, condicionando suas ações às dos demais na tarefa de buscar o cumprimento de seus horários agendados de pouso e decolagem.

A competição em um cenário modelado como um jogo não garante que os agentes sejam atendidos em suas preferências estritas, o que força situações de negociação. Surge então a figura do árbitro, que define políticas de validação de ofertas e aloca recursos de maneira impositiva aos agentes no caso de negociações infrutíferas (Yildiz, 2010). No CoDMAN, os agentes são as aeronaves, que negociam entre si a ocupação dos slots de decolagem.

Esta abordagem transfere diretamente aos agentes racionais uma parte das responsabilidades dos controladores de torre nos aeroportos. Os agentes atuarão em um cenário onde a força de negociação será fator determinante no sucesso da alocação, sendo satisfeitas todas as exigências operacionais impostas por legislação e por restrições aeroportuárias.

\subsection{Modelagem do cenário}

O cenário é modelado com base nos parâmetros operacionais do aeroporto e da área terminal:

$F$ : conjunto dos voos ativos no aeroporto e na área terminal (TMA), composto pelo conjunto de aeronaves em solo $\left(F_{g}\right)$ ou em voo $\left(F_{a}\right)$;

$F_{a}^{-}$e $F_{g}^{-}$: voos no ar e em solo, respectivamente, que não participam da negociação de slots;

$I_{p}$ : capacidade aeroportuária instalada, determinada pelo número de fingers operacionais $\left(I_{p}^{f}\right)$ e pelo número de runways que podem ser utilizadas simultaneamente $\left(I_{p}^{r}\right)$;

$C_{a}(t)$ : capacidade de aterrissagens no aeroporto no instante $t$;

$C_{d}(t)$ : capacidade de decolagens no aeroporto no instante $t$;

$Q_{a}$ : conjunto das aeronaves na TMA aguardando autorização para pouso;

$Q_{d}$ : conjunto das aeronaves no pátio do aeroporto aguardando autorização para decolagem;

$K$ : custo total dos atrasos.

A aeronave é inserida no conjunto $Q_{d}$ assim que solicita autorização de push-back, tornando-se um voo ativo. A aeronave sai deste conjunto ao decolar, sendo então colocada em um conjunto denominado $F_{a}^{-}$. Em contrapartida, um voo é removido do conjunto $Q_{a}$ assim que a aeronave toca a pista de pouso, passando a integrar o conjunto $F_{g}^{-}$. As aeronaves presentes nos conjuntos $F_{a}^{-}$e $F_{g}^{-}$ não possuem interesse nas negociações e seu impacto se resume na alteração da capacidade de gerenciamento do aeroporto.

O número de pistas utilizadas para aterrissagem e decolagem no instante $t$ são, respectivamente, iguais a $I_{a}(t)$ e $I_{d}(t)$. A capacidade de decolagem é definida pelo volume de aeronaves que o aeroporto pode despachar, obtido na Equação 1. Este número é simplesmente o número de pistas disponíveis para utilização no instante $t$, sendo priorizados os pousos para a utilização das pistas. Vale observar que não é feito esforço no sequenciamento de aterrissagens, que são processadas segundo uma fila simples na ordem FIFO (first in, first out).

$$
C_{d}(t)=I_{p}^{r}-\left(I_{a}(t)+I_{d}(t)\right)
$$

A capacidade de aterrissagem é descrita pela Equação 2. O fator $I_{p}^{f}-F_{g}^{-}$define a capacidade de ocupação do pátio do aeroporto, enquanto que $\mathrm{o}$ fator

$$
C_{a}(t)=\min \left\{I_{p}^{f}-F_{g}^{-}, I_{p}^{r}-\left(I_{a}(t)+I_{d}(t)\right)\right\}
$$

$I_{p}^{r}-\left(I_{a}(t)+I_{d}(t)\right)$ define a quantidade de pistas livres para operação no instante $t$.

A Equação 3 define o custo total dos atrasos dos $n$ voos ativos através da somatória dos custos dos atrasos inerentes a cada voo $i=1, \ldots, n$.

$$
K=\sum_{i=1}^{n} k_{i}
$$




\subsection{Modelagem das aeronaves}

Cada aeronave é um agente atuando no cenário, e tem definidos os atributos:

$t_{d}$ : horário de decolagem previamente alocado com base no plano de voo;

$t_{a}$ : horário previsto de aterrissagem no aeroporto de destino;

$v$ : velocidade de cruzeiro, em milhas náuticas por hora;

$t_{f}$ : duração estimada do voo até seu destino, em horas;

$c$ : ocupação máxima da aeronave, em número de passageiros;

$D$ : máximo período de atraso aceitável para a aeronave, em minutos;

$p$ : número de passageiros presentes na aeronave;

$B$ : porte da aeronave (pequeno, médio ou grande), mapeado em um número inteiro no intervalo $[1,3]$;

$w$ : largura (wingspan) da aeronave, normalizado para milhas náuticas;

$\sigma$ : significância da aeronave;

$l$ : atraso imposto à aeronave, em minutos;

$k$ : custo ponderado individual do atraso, que é a função de recompensa da aeronave.

O fator $\frac{B}{w}$ expressa o tamanho da aeronave e é usado para a separação mínima entre as decolagens, motivada pelo surgimento de esteiras de turbulência quando da movimentação das aeronaves. Ainda, pressupõe-se que o custo operacional é mais elevado em aeronaves de maior porte. O mapeamento é feito com base na tabela de grupos de projeto (design groups) da Federal Aviation Administration (Ashford et al., 2011):

- grupo I: pequeno porte;

- grupos II, III e IV: médio porte;

- grupos V e VI: grande porte.

A Equação 4 define a significância da aeronave como uma medida adimensional determinada em termos de sua lotação, seu porte e da distância ao aeroporto de destino, calculada em dezenas de milhas náuticas. Uma aeronave que apresenta estas características mais elevadas é considerada mais significativa para o cenário, pois possui um maior impacto operacional associado.

$$
\sigma=v t_{f} \frac{B}{w} \frac{p}{c}
$$

O índice de significância é utilizado para o cálculo do custo ponderado do atraso individual, dado pela Equação 5 . O custo é um valor genérico que reflete o impacto do atraso para a aeronave. A quantidade de passageiros como um dos atributos da significância reflete o fato de

$$
k=\frac{l \sigma}{D}
$$

que os custos operacionais são maiores para voos mais utilizados, e cada passageiro é afetado por um custo individual desconhecido pela companhia.

\subsection{Negociação de slots}

Primeiramente, as aeronaves são alocadas na fila de slots com a organização FIFO. Cada aeronave $F_{i}$ é inserida no sequenciamento com o objetivo de anular $k_{i}$, o que de fato ocorre na situação ideal. No entanto, ao desejar ocupar uma posição atribuída a outro voo, a aeronave inserida força a manipulação da fila, imprimindo atrasos a certos voos. $\mathrm{O}$ atraso real de um voo em estado de espera em solo é igual a $t_{r}-t_{d}$, sendo $t_{r}$ o horário real de decolagem.

A negociação entre as aeronaves é feita de maneira colaborativa com a observância das premissas do CDM. O objetivo da barganha é a minimização do custo global dos atrasos, com o menor atraso individual possível. Para tanto, uma aeronave adota uma das seguintes ações: a) tenta capturar o slot seguinte; b) cede seu slot para outra aeronave; ou c) permanece em seu slot.

A atividade dos voos no tráfego exige constante monitoramento do desempenho das aeronaves, sendo escolhida a janela de duas horas de observação a partir do horário corrente na simulação (esta janela de tempo foi escolhida porque o planejamento tático do voo se inicia duas horas antes de sua execução). Detectado o conflito de interesses, os agentes entram em negociação e recebem uma recompensa. Este valor não é diretamente utilizado como atributo de prioridade no sequenciamento, mas é útil para a mensuração da qualidade da barganha. A negociação dá às aeronaves uma oportunidade de ajustarem seus slots tendo como cerne os seus interesses individuais, ou seja, busca-se de maneira egoísta a melhor posição possível na fila de decolagens. Seus interesses são submetidos ao crivo do aeroporto, que valida ou não a oferta.

Sendo assim, cada aeronave, exercendo o papel de proponente, calcula uma oferta aceitável. A consequência é a elaboração de uma oferta que lhe trará maior benefício, ao passo que as restrições do árbitro são observadas e a aeronave oponente acaba por considerar plausível tal oferta (mesmo que esta não seja aceita $a$ priori). A proposição de ofertas consiste na sugestão de uma das ações possíveis, com base na configuração atualizada dos parâmetros da aeronave. O relaxamento (ou fator de desconto) das ofertas é incrementado a cada iteração. Isto faz com que a aeronave seja mais agressiva ou mais retraída nas ofertas subsequentes. Como este é um jogo de informação perfeita, o próprio conhecimento a respeito dos demais agentes torna a aeronave uma entidade mais cooperativa ao reconhecer que certos agentes possuem prioridade.

O gradiente de impaciência $\gamma_{i}$ é calculado a partir do horário de decolagem da aeronave $f_{i}$. Este parâmetro, descrito na Equação 6, representa a urgência da aeronave em que se conclua a negociação. Nesta equação, $w$ é o máximo período no qual ainda é possível negociar, $t_{o b t}$ é o horário de partida e $t_{c u r}$ é o horário atual. Assim, tem-se que, quanto mais alto for $\gamma_{i}$, mais próximo está o horário de decolagem da aeronave $i$. Ainda, $i$ não aceita negociar se $\gamma_{i}$ for igual a 1 .

$$
\gamma=\frac{w}{\max \left(w, t_{o b t}-t_{c u r}\right)}
$$


Finalmente, o fator de desconto é obtido pela Equação 7, de modo que são ponderados os gradientes de impaciência as aeronaves envolvidas na negociação.

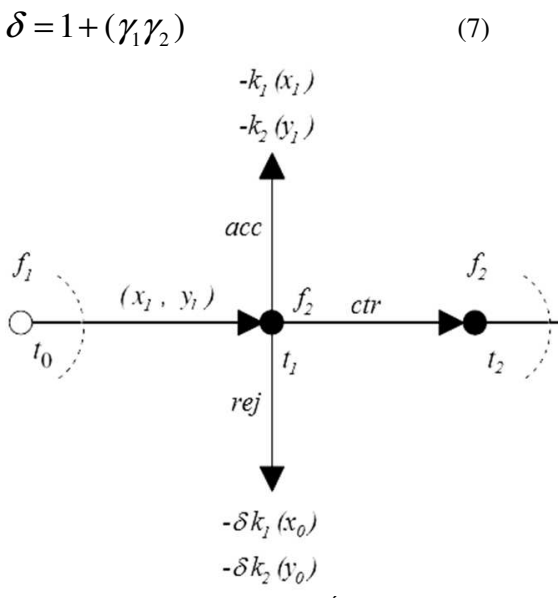

Figura 1. Arvore de Rubinstein adaptada ao CoDMAN

O fluxo básico do processo de negociação é o seguinte: a fila de decolagens é completamente percorrida a partir da aeronave cujo horário de decolagem alocado é o mais próximo ao horário corrente. Se a aeronave possuir interesse em negociar, ela calcula uma oferta e a envia à aeronave que está imediatamente à sua frente na fila. Se aceita, esta ação é aplicada e a aeronave seguinte na fila é avaliada. Caso contrário, o fator de desconto é atualizado e uma nova oferta é elaborada, desta vez pela aeronave oponente. Eventualmente, a negociação entre as duas aeronaves não culminará num acordo e a entidade representativa do aeroporto decidirá pela oferta que proporciona o melhor desempenho do cenário global.

\subsection{Negociação de slots no protocolo de Rubinstein}

A negociação no CoDMAN é matematicamente modelada de modo a considerar o aspecto dinâmico da interação entre os agentes. Para tal, o jogo é formalizado em uma sequência cronológica das ações utilizadas, o que permite que o agente elabore um plano de ação em qualquer momento onde uma decisão precisa ser tomada. Neste jogo, negociam duas aeronaves com horários de decolagem conflitantes. $\mathrm{O}$ conflito imprime um atraso à aeronave que deseja ocupar o slot já ocupado. Para os casos que não demandam a negociação, entende-se que o jogo já está em estado de equilíbrio.

Quando duas aeronaves $f_{1}$ e $f_{2}$ iniciam uma negociação, a aeronave $f_{1}$ sugere à aeronave $f_{2}$ que esta avance $(a d v)$ ou atrase $(d e l)$ seu horário de partida, sendo possível ainda a permuta de slots ( $s w p)$. Dadas estas três alternativas, a aeronave $f_{2}$ pode escolher uma das três ações:

1. acc: aceitar a oferta e receber a recompensa cabível;

2. rej: rejeitar a oferta e manter seu custo de atraso, enquanto arca com a intervenção do árbitro;

3. ctr: elaborar uma contraoferta, reiniciando o processo de negociação e tornando-se o agente ativo da barganha.

No caso da negociação de slots, não há unidade de valor divisível, uma vez que a barganha consiste em imprimir ao oponente uma alteração no seu horário de decolagem. As recompensas dos jogadores são assimétricas, pois a soma destas não é limitada a um intervalo específico como no protocolo clássico de Rubinstein. A recompensa consiste na Equação 5, ou seja, a negociação mais interessante é aquela na qual o custo do atraso é minimizado.

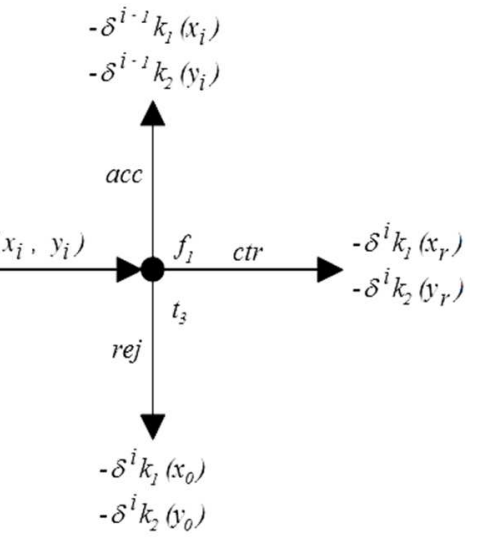

Para fins de simplificação, a utilidade é um número negativo que o jogador tenta aproximar a zero.

A Figura 1 ilustra o protocolo de Rubinstein adaptado ao CoDMAN. Cada oferta consiste na proposição de uma tupla $\left(x_{i}, y_{i}\right)$ tal que $x_{i}$ e $y_{i}$ são números reais, $x_{i}$ é o atraso atribuído à aeronave $f_{1}$ e $y_{i}$ é o atraso atribuído à aeronave $f_{2}$ num instante $i$.

Pelo modelo, o jogo pode prosseguir indefinidamente, mas é estabelecido um limite de rodadas de negociação, o que pode culminar em um impasse. Neste caso, o árbitro aplica alguma das ofertas anteriores tal que o custo para o cenário aeroportuário seja o menor possível. Esta situação é formalizada na Equação 8, que mostra como $f_{1}$ e $f_{2}$ recebem suas recompensas. $\mathrm{O}$ valor $K^{\prime}\left(x_{i}, y_{i}\right)$ é o custo global resultante da aplicação do atraso $x_{i}$ à aeronave $f_{1}$ e do atraso $y_{i}$ à aeronave $f_{2}$, na $i$-ésima oferta. Os valores $x_{0}$ e $y_{0}$ equivalem aos valores correntes de atraso para as aeronaves.

$$
\begin{gathered}
\left(-\delta^{i} k_{1}\left(x_{r}\right) ;-\delta^{i} k_{2}\left(y_{r}\right)\right) \mid \mathrm{K}^{\prime}\left(\mathrm{x}_{\mathrm{r}} ; \mathrm{y}_{\mathrm{r}}\right)=\min \left\{\mathrm{K}^{\prime}\left(\mathrm{x}_{\mathrm{i}} ; \mathrm{y}_{\mathrm{i}}\right)\right\}, \\
0 \leq \mathrm{r} \leq \mathrm{i}
\end{gathered}
$$

A rejeição de ofertas aumenta o custo total do processo de barganha e, por isso, o fator de desconto $\delta$ é incrementado. $\mathrm{Na}$ implementação, este fator é calculado a partir da ponderação do horário de off-block das aeronaves. A rejeição geralmente está associada a um alto valor de $\delta$, ou seja, quando a aeronave oponente já está muito próxima ao horário de decolagem. A utilização desta estratégia conserva o status quo do cenário, todavia sendo extremamente desestimulante no processo de barganha. Assim, por indução retroativa na árvore da Figura 1, o único equilíbrio obtido faz com que o jogo termine na primeira rodada, uma vez que a continuidade da barganha faz com que o payoff esperado seja menor a cada nova oferta. Este equilíbrio é eficiente, pois não há perda com a espera. Portanto, este jogo é estrategicamente consistente.

\section{SIMULAÇÕES E RESULTADOS}

O sistema foi desenvolvido com o uso da linguagem $\mathrm{C}++$, uma linguagem bastante utilizada na programação 
Tabela 1. Desempenho das aeronaves com alocação estática de horário de partida

\begin{tabular}{lll}
\hline Atributo & Sem negociação & Com negociação \\
\hline Atraso médio por aeronave atrasada & 3,48 minutos & 3,26 minutos \\
Custo médio por aeronave atrasada & 643,95 & 476,193 \\
Atraso total & 73 minutos & 62 minutos \\
Desvio-padrão dos atrasos & 0,9213 & 1,0532 \\
Desvio-padrão dos custos de atraso & 229,165 & 182,427 \\
Custo total dos atrasos para o cenário & 13522,9 & 9047,67 \\
\hline
\end{tabular}

orientada a objetos. Em cada cenário, é calculado o custo total dos atrasos e o seu desvio-padrão. Este cálculo informa o quão justo é o sequenciamento de slots resultante do processo de negociação. As simulações consistem em avaliar a pertinência do protocolo nas etapas de planejamento pré-tático e tático, com a modelagem de situações nas quais a demanda de utilização é variada. No total, foram analisados os planos de voo de 202 aeronaves que decolam do Aeroporto Internacional de Brasília (SBBR).

\subsection{Descrição e simulação dos cenários}

Todos os voos partem do Aeroporto Internacional de Brasília, que possui duas runways operacionais que podem ser usadas simultaneamente. No entanto, o Aeroporto Santa Genoveva, em Goiânia (SBGO), também recebe e despacha voos de/para a TMA-Brasília. Por este motivo, os planos de voo que possuem como origem ou destino os aeroportos SBBR e SBGO são incluídos no modelo.

A fila primordial de decolagens é ajustada para a garantia da separação mínima entre as aeronaves. Esta operação introduz alguns atrasos, o que faz com que alguns voos demonstrem interesse em slots melhores. A fila é percorrida e tais aeronaves são identificadas. É feita a tentativa de negociação com o vizinho à frente, que decolará primeiro, na tentativa de ajuste de horário de decolagem. O primeiro caso de simulação considera apenas os planos de voo para o sequenciamento, enquanto que os demais casos de simulação dinâmica consideram demandas simultâneas por decolagens e aterrissagens.

\subsubsection{Caso 1: alocação estática}

O primeiro caso de simulação foi concebido a fim de que fosse elaborado o sequenciamento estático de partidas, ou seja, os voos são considerados na fase de planejamento estratégico. No primeiro momento, todos os voos são ordenados na ordem FIFO de acordo com seu horário esperado de off-block (EOBT). Esta configuração primária da fila é a base para os demais casos de simulação. No caso 1 , os dados utilizados se limitam apenas a 202 planos de voo válidos, ou seja, não há inserção de dados em tempo real.

A fila inicial é ajustada com o objetivo de se garantir a separação mínima entre as aeronaves. Esta operação acaba por inserir atrasos na fila antes mesmo da aplicação de medidas restritivas, logo algumas aeronaves podem apresentar interesse direto na obtenção de slots mais favoráveis. A negociação é então estabelecida entre estas aeronaves e seus vizinhos imediatos em uma tentativa de ajuste nos seus horários de decolagem.

O desempenho do cenário antes e depois da negociação pode ser observado na Tabela 1 . Verifica-se que o atraso total na fila foi reduzido de 73 minutos para 62 minutos e que o custo médio para voos atrasados foi redu- zido em cerca de $26 \%$. O principal efeito do processo de negociação incide sobre o custo total do cenário, que reduziu em $33 \%$. Ainda, o desvio-padrão para os custos de atraso foi diminuído. Isto equivale a dizer que os custos dos atrasos foram distribuídos de maneira mais justa entre as aeronaves, devido ao fato de que a preocupação é com a variável custo de atraso, ao invés da variável atraso em si.

\subsubsection{Caso2: alocação dinâmica simples}

A necessidade da aplicação de separação mínima entre os voos é verificada a cada minuto, uma vez que será eventualmente necessário introduzir atrasos não planejados na fila quando aplicada uma medida restritiva de espera em solo. Isto ocorre em virtude da elevada demanda por aterrissagens ou por conflitos nos horários de decolagem entre duas ou mais aeronaves.

$\mathrm{O}$ primeiro fator influencia diretamente a capacidade do aeródromo, devendo ser respeitadas as limitações quanto à utilização das pistas de movimentação. Quando a capacidade de decolagens é nula (não é possível despachar para a TMA nenhuma aeronave em um dado instante $t$ ), é necessário aplicar o atraso de segurança para a próxima aeronave da fila, se sua decolagem está agendada para o mesmo instante.

Ao atrasar a primeira aeronave da fila de decolagens, que já estava pronta para a execução do voo, deve ser novamente aplicado o procedimento para a separação mínima de segurança para as aeronaves subsequentes. Assim, todas as aeronaves da fila de decolagens que estiverem à frente do primeiro slot livre sofrerão atraso e tal slot será ocupado. Este procedimento impede que haja conflito nos horários calculados para partida. Neste procedimento, deseja-se novamente distribuir de maneira justa o custo dos atrasos imprevistos.

Para este caso de simulação, foram analisados 518 voos que impactaram a TMA Brasília, sendo que 85 deles não participaram da movimentação do aeródromo SBBR, mas impactaram a TMA. Dos restantes, 202 decolaram do aeroporto e 231 aterrissaram. Como esperado, a demanda por aterrissagens afetou o desempenho da fila, fazendo com que 43 voos decolassem fora do horário previsto. $\mathrm{O}$ atraso total do cenário foi de 86 minutos, devido ao fato de que foi necessário aplicar a medida restritiva de espera em solo a 7 aeronaves.

A Tabela 2 detalha os dados da simulação. A quantidade de voos fora do horário aumentou de 43 para 44 após as negociações, porém havendo uma diminuição do atraso total do cenário, de 86 minutos para 73 minutos, sendo portanto minimizado o atraso médio das aeronaves. A redução de 264,16 para 199,41 no desvio-padrão do custo dos atrasos demonstra que os custos foram distribuídos de modo a uniformizar o desempenho das aeronaves. Por fim, o custo total do cenário foi diminuído em cerca de 
RIBEIRO, V. F.; WEIGANG, L.

Tabela 2. Desempenho das aeronaves com alocação dinâmica de horário de partida

\begin{tabular}{lll}
\hline Atributo & Sem negociação & Com negociação \\
\hline Atraso médio por aeronave atrasada & 2 minutos & 1,66 minutos \\
Custo médio por aeronave atrasada & 385,884 & 272,286 \\
Atraso total & 86 minutos & 73 minutos \\
Desvio-padrão dos atrasos & 0,980878 & 1,0429 \\
Desvio-padrão dos custos de atraso & 264,161 & 199,406 \\
Custo total dos atrasos para o cenário & 16593 & 11980,6 \\
\hline
\end{tabular}

Tabela 3. Avaliação da degradação do cenário quando uma runway é removida

\begin{tabular}{lll}
\hline Atributo & Sem negociação & Com negociação \\
\hline Atraso médio por aeronave atrasada & 3,23 minutos & 3,01 minutos \\
Custo médio por aeronave atrasada & 595,233 & 544,848 \\
Atraso total & 329 minutos & 319 minutos \\
Desvio-padrão dos atrasos & 2,34359 & 2,38823 \\
Desvio-padrão dos custos de atraso & 570,475 & 523,71 \\
Custo total dos atrasos para o cenário & 60713,8 & 56119,4 \\
\hline
\end{tabular}

Tabela 4. Desempenho do cenário quando uma runway é adicionada

\begin{tabular}{lll}
\hline Atributo & Sem negociação & Com negociação \\
\hline Atraso médio por aeronave atrasada & 2,09 minutos & 1,69 minutos \\
Custo médio por aeronave atrasada & 396,142 & 277,265 \\
Atraso total & 73 minutos & 61 minutos \\
Desvio-padrão dos atrasos & 0,932068 & 0,98894 \\
Desvio-padrão dos custos de atraso & 243,83 & 192,332 \\
Custo total dos atrasos para o cenário & 13865 & 9981,53 \\
\hline
\end{tabular}

$27,8 \%$, comprovando a melhoria na qualidade da sequência de decolagens.

\subsubsection{Caso 3: redução do número de runways}

O terceiro caso de simulação considera o impacto na infraestrutura aeroportuária ao se reduzir o número de pistas de decolagem e aterrissagem. O objetivo aqui é precisamente avaliar a influência da infraestrutura aeroportuária na eficiência das operações de decolagem. Os planos de voo e as informações de radar permanecem inalterados, o que aumenta a razão demanda/recursos. Devido à escassez dos recursos aeroportuários, espera-se uma degradação do processo frente ao cenário padrão, discutido na alocação dinâmica simples do caso 2 .

$\mathrm{O}$ aeroporto de Brasília conta com duas pistas destinadas aos movimentos de decolagem e aterrissagem, que é uma situação incomum entre os aeroportos brasileiros. De fato, a maioria dos aeroportos coordenados brasileiros conta com somente uma runway. Logo, a remoção de uma runway reflete a realidade enfrentada atualmente no Brasil. Nestes moldes, foi elaborada uma nova simulação. A degradação do cenário é nitidamente perceptível. A primeira consequência é o aumento da aplicação das medidas restritivas, devido ao fato de que a infraestrutura aeroportuária rapidamente atinge sua capacidade máxima de operação.

O desempenho do aeródromo pode ser analisado na Tabela 3. Desta vez, mais aeronaves desejam negociar, tornando o processo de barganha menos cooperativo. Por conseguinte, as otimizações foram mais modestas neste caso de simulação, com o custo total do cenário diminuído em $7,6 \%$. Outra conclusão interessante é o fato de que a remoção de uma pista aumenta em média $65 \%$ o custo do atraso individual das aeronaves, mas eleva em quase quatro vezes o custo do desempenho do cenário.

\subsubsection{Caso 4: inclusão de runways adicionais}

A última simulação considera o impacto na infraestrutura aeroportuária ao se ampliar o número de pistas de movimentação. Espera-se uma melhoria significativa no desempenho, pois o aumento da capacidade, em hipótese, diminui a quantidade de medidas restritivas aplicadas, bem como aumenta a quantidade de voos que podem ser movimentados simultaneamente.

Foi virtualmente adicionada uma nova pista de rolagem ao aeroporto, que agora contém três runways por onde é possível despachar e receber aeronaves. Assim como no caso da redução da capacidade, o aumento da capacidade causa um impacto bastante sensível ao desempenho do cenário. No entanto, ao contrário do caso anterior, este impacto é positivo. Foi possível receber 231 aeronaves, enquanto que 229 aeronaves aterrissaram quando havia apenas uma pista. Não houve a necessidade de aplicação de medidas restritivas em momento algum e o atraso médio, bem como o seu custo associado, foram minimizados. O desvio-padrão destes custos também caiu, mostrando que a fila está mais equilibrada. Por fim, o custo do cenário caiu em cerca de $28 \%$, conforme apresenta a Tabela 4.

\subsection{Avaliação dos resultados}

No sequenciamento estático da fila de decolagens, não há interferência de fatores externos ao aeroporto, tampouco existe a preocupação com a capacidade instantânea do aeródromo. Esta exigência é atendida pelas simulações dinâmicas, que apresentam a redução de custo mais significativa para o sequenciamento dinâmico simples. Ainda assim, a diminuição de $33 \%$ nos custos do sequenciamento estático evidenciam os benefícios de um planejamento estratégico adequado. 
Ao ser observado o cenário padrão, com alocação dinâmica simples, a otimização dos custos foi de $27,8 \%$. O desvio-padrão dos custos foi o que sofreu a maior redução, demonstrando que esta alocação é a que melhor distribui os custos dos atrasos pelas aeronaves.

Com a capacidade reduzida, o protocolo de negociação perde sua eficiência. A causa disto é a inflexibilidade da fila em virtude da diminuição de slots livres conforme o tempo evolui. Por este motivo, a quantidade de ofertas que sugerem a troca de posições na fila (swap) é aumentada, ocorrendo então um maior índice de rejeições por parte das aeronaves oponentes.

Quando a capacidade do aeródromo é ampliada, o custo total dos atrasos naturalmente diminui. Conforme esperado, neste caso o cenário obteve o melhor resultado no que tange ao custo total dos atrasos, com uma redução de $28 \%$. Isto se deve ao fato de que os atrasos efetivamente diminuem, mesmo que o minuto de atraso não tenha seu custo diminuído. Apesar de ser uma boa solução, ela não é realista, pois existe a premissa de que a demanda não será alterada no caso de investimentos na infraestrutura aeroportuária.

\section{CONCLUSÕES}

Os resultados obtidos demonstram a consistência e aplicabilidade da solução apresentada. Foi demonstrado que um cenário modelado segundo os princípios do CDM de fato se comporta como um jogo cooperativo multiagentes com informação completa.

A solução apresentada aborda de maneira inovadora o problema da alocação de slots para decolagens, usando a Teoria dos Jogos para o sequenciamento de partidas. Esta tarefa de sequenciamento foi adequadamente modelada segundo o Protocolo de Rubinstein para ofertas alternadas.

Foi desenvolvida uma ferramenta de auxílio à tomada de decisão por parte do agente humano em um ambiente complexo. Este agente é o controlador de tráfego aéreo, atualmente dispondo somente de meios de visualização de dados. A expectativa é de que esta ferramenta diminua a carga de trabalho do agente humano no processo de sequenciamento de partidas, aumentando a segurança e eficiência operacionais nas atividades da torre de controle.

O protótipo viabilizou um nível primordial de comunicação entre as aeronaves, as companhias aéreas e os controladores do aeródromo a fim de que fossem minimizados e equilibrados os custos associados aos atrasos no ambiente aeroportuário. O compartilhamento de informações proporcionado pela ferramenta simula adequadamente o processo de atividades do CDM.

$\mathrm{O}$ estudo ainda se encontra na fase de pesquisa, desejando-se a integração futura com sistemas AMAN (Arrival Management) eventualmente desenvolvidos. Ainda, apesar de fornecer soluções calculadas como ótimas, espera-se que o sistema não ignore a experiência do controlador, que decidirá pela aplicação da solução apresentada, sendo possível alterar o sequenciamento sugerido.

\section{REFERÊNCIAS}

A. M. F. Crespo. Módulo de avaliação e apoio à decisão: uma aplicação de aprendizagem por reforço no gerenciamento tático do fluxo de tráfego aéreo. Master's thesis, University of Brasília - Science of Computation Department, 2010.

M. Groppe, R. Paglieri, and D. Harris. Field observations during Airport-CDM turn-round process: Study on airline's approach to TOBT assignment. EUROCONTROL Experimental Centre, 2010.

Comando da Aeronáutica. Demanda Detalhada dos Aeroportos Brasileiros, volume 1. Brazilian Institute of Civil Aviation, 2005.

M. Yildiz. Nash meets Rubinstein in final-offer arbitration. Massachusetts Institute of Technology, Economics Department, November 2010. DOI: 10.1016/j.econlet.2010.10.020

A. C. Arruda Jr. Aprendizagem por reforço aplicada à análise de impacto no controle de fluxo de tráfego aéreo. Master's thesis, University of Brasília - Science of Computation Department, 2009.

C. A. Holt and A. E. Roth. The Nash equilibrium: A perspective. Proceedings of the National Academy of Sciences of the United States, 101(12): 3999 - 4002, 2004. DOI: 10.1073/pnas. 0308738101

L. Weigang, B.B. Souza, A.M.F. Crespo, and D.P. Alves. Decision support system in tactical air traffic flow management for air traffic flow controllers. Journal of Air Transport Management, 14(6):329 - 336, 2008.

International Civil Aviation Organization. Manual on Simultaneous Operations on Parallel or Near-Parallel Instrument Runways (SOIR). International Civil Aviation Organization, 1 edition, 2004.

D. Bertsimas and S. Gupta. Fairness in air traffic flow management. INFORMS Meeting, San Diego - CA, USA, 2009.

V. F. Ribeiro. Decisão colaborativa com utilização de Teoria dos Jogos para o sequenciamento de partidas em aeroportos. Master's thesis, University of Brasília - Science of Computation Department, 2013.

EUROCONTROL. Airport CDM Implementation - The Manual for Collaborative Decision Making. Eurocontrol, 2010.

T. L. Turocy and B. von Stengel. Game Theory. Number 5. Computational, Discrete and Applicable Mathematics, 2001. CDAM Research Report LSECDAM-2001-09.

A. L. Manocchio. Teoria dos jogos e negociação. Undergraduate thesis, Mathematics Applied to Business Course, University of São Paulo, 2007.

T. Vossen, M. Ball. Optimization and mediated bartering models for ground delay programs. Naval Research Logistics 53 (1), 7590, 2006. DOI: 10.1002/nav.20123

M. Ball, R. Hoffman, D. Knorr, J. Wetherly, and M. Wambsganss. Assessing the benefits of collaborative decision making in air traffic flow management. 3rd USA/Europe Air Traffic Management Research and Development Seminar, April 2000 .

DECEA. Implementação Operacional do Conceito de Navegação Baseada em Performance (PBN) no Espaço Aéreo Brasileiro. Circular de Informação Aeronáutica 24/13. 12/12/2013.

R. Goldman. A-CDM in New York KJFK Runway Construction and Impact on Operations. In Advanced ATM Techniques Sym- 
posium and Workshops, 4 - 6 November 2013, ICAO Headquarters, Montréal.

N. J. Ashford, S. Mumayiz and P. H. Wright. Airport Engineering: Planning, Design and Development of 21st Century Airports. 4th edition, John Wiley \& Sons, 2011. DOI: 10.1002/9780470950074 